\title{
1. Data collection procedure equivalence in emerging economy market research
}

\author{
Pervez N Ghauri and Agnieszka Chidlow
}

\section{INTRODUCTION}

An increasing interdependence among international companies and emerging economies has led to an unprecedented surge in international trade and investment activities, forcing both managers and researchers to seek information and make sense of cross-country data. However, undertaking international research based on multi-country surveys, especially in emerging economies, has long been acknowledged as a difficult task (Przeworski and Teune, 1966; Sekaran, 1983; Nasif et al., 1991; Cavusgil and Das, 1997; Berry, 1999). While workable solutions have been offered in areas such as questionnaire development and data analysis techniques (Jobber and Saunders 1988; Jobber et al., 1991; Harzing, 1997; Brock, 2003; Reynolds et al., 2003; Chidlow et al., 2014), achieving equivalence in data collection procedures and methods still remains to be resolved (Kjeldgaard et al., 2006; Yaprak, 2006; Hult et al., 2008, Piekkari et al., 2009). Data collection procedure equivalence, including comparability with regard to research instrument equivalence (e.g. face-to-face interviews, mail surveys, etc.), and sampling coverage and survey administration procedures (Craig and Douglas, 2000; Hult et al., 2008; Chidlow et al., 2015), if not achieved, threaten the main purpose of conducting research in the context of emerging economies.

As postal surveys still dominate other methods of cross-country data gathering (Adler, 1983; Peng et al., 1991; Yang et al., 2006; Chidlow et al., 2015), the aim of this chapter is to investigate 'if' and 'how' scholars report postal survey administration procedures, and whether or not an equivalence of data collection procedures can be established in emerging economy market research. In line with other researchers (e.g. Sekaren, 1983; Nasif et al., 1991; Hult et al., 2008) it is our belief that establishing this is an important step towards achieving overall comparability and equivalence in cross-national research.

Moreover, there is a great need to go deeper into the data collection method equivalence issue to see whether the data collection procedures proposed by scholars (e.g. Dillman, 1978 and 1999; Ghauri and Gronhaug, 2010) are followed in cross-national research or not. This is because the equivalence in data collection procedure is the key to achieving equivalence in collected data. 
In this chapter, attention will be drawn first to the issue of data collection procedure equivalence. Second, the focus will be on multiple-contacts for mail surveys proposed by Dillman $(1978,1999)$. These could be used to ensure equivalence in administration and response. Third, attention is paid to the effectiveness of Dillman's framework to cross-country research. Fourth, the analytical approach used to examine our data is presented. Last, in the conclusions, the importance of this chapter is summarised as a useful basis to scholars embarking upon a journey of ensuring data collection procedure equivalence during the gathering process of cross-national data from emerging economies.

\section{DATA COLLECTION PROCEDURE EQUIVALENCE}

Going beyond the borders of one country, does not mean that comparative research differs from any other type of social science inquiry with respect to its rigour (Chidlow et al., 2015). Hence, like other social science analyses, crossnational research requires cautious procedures to yield validity and reliability in more heterogeneous settings, to enable researchers to ensure the generalisability of implications across borders (Hult et al., 2008).

With respect to equivalence, methodological issues in cross-country analysis have been subjected to investigation by many academics across several disciplines over the past four decades (Przeworski and Teune, 1966; Berry and Dasen, 1974; Green and White, 1976; Sekaran, 1981; Adler, 1983; Nasif et al., 1991; Cavusgil and Das, 1997; Coviello and Jones, 2004; Herk et al., 2005; Hult et al., 2008).

Craig and Douglas (2000, p. 141) define equivalence as 'data that have, as far as possible, the same meaning or interpretation, and the same level of accuracy, precision of measurement, or reliability in all countries and cultures'. This implies that 'the elements of a research design have the same meaning and can be applied in the same way, in different national contexts' (Hult et al., 2008, p. 1027).

The idea of equivalence is based on two approaches: emic and etic. ${ }^{1}$ The aim of an emic approach is to examine a phenomenon with specific concepts used in a particular culture. However, the goal of an etic approach is to study a phenomenon to develop a universal law that can identify commonalities and differences across cultures, using equivalent concepts, metrics or indicators (Cavusgil and Das, 1997; Schaffer and Riordan, 2003; Ghauri and Gronhang, 2010). The challenge that faces cross-national scholars lies in the choice between these two approaches, known in the management literature as the eticemic dilemma (Adler, 1983).

Following the work in comparative research by Sekaran (1983), generally five forms of equivalence are distinguished: functional equivalence; 
instrumentation; data collection; sampling design; and data analysis. Numerous researchers in this field - for example, Adler (1983), Nasif et al. (1991), Peng et al. (1991), Cavusgil and Das (1997) and Hult et al. (2008) - have supported the above categorisation. In brief, the functional equivalence is linked to the roles of objects or behaviours in different countries. Instrumentation equivalence takes account of equivalence in translation, concepts and syntax. Data collection equivalence stresses the importance of comparability across cultures with regard to the sources of data, the methods of eliciting data, constructs and questionnaire items. Sampling equivalence consists of such issues as representativeness and matching of samples across cultures. Data analysis equivalence demonstrates whether or not cross-national data can be taken, analysed and composed as equivalent to provide comparable and generalisable results.

Following the establishment of the equivalence framework in comparative research, Cavusgil and Das (1997) developed a seven-stage methodology model for conducting cross-national research (Figure 1.1). In their generic model, they address various equivalence issues that have to be accounted for when undertaking such research (e.g. conceptual equivalence and functional equivalence). However, in our view they do not pay sufficient attention to data collection procedure equivalence that can be used, for example, in a postal survey. Hence, building on their work, and mainly focusing on the data collection stage of their model, ${ }^{2}$ it is our hope to demonstrate the importance of data collection procedure equivalence in a mail survey, which is an integral element of data collection equivalence.

From Figure 1.1 it is evident that issues such as the time period, the type of research, the interviewer's status and the response rate ought to be seriously considered by researchers when planning the collection of cross-national data. Within this type of research, it is also apparent that the collected data could be either primary or secondary. When, for example, the latter is undertaken, via a postal survey, we suggest that Dillman's (1978) data collection administration techniques could be used to ensure equivalence not only in the administration process but also in the response rate, leading to the cross-national data being equivalent as a whole.

In our view data collection equivalence is essential for knowledge creation in the field of emerging economy market research as it, for example, influences the response rate, which represents a generally accepted proxy for nonresponse error.

When designing comparative research close attention should be paid, among other issues, to data collection to ensure comparability across surveyed countries. Such attention is needed because many countries have noticeably different social systems, literacy rates, and cultural norms and values. Even in countries where the same language is spoken there might be different vocabulary in use 


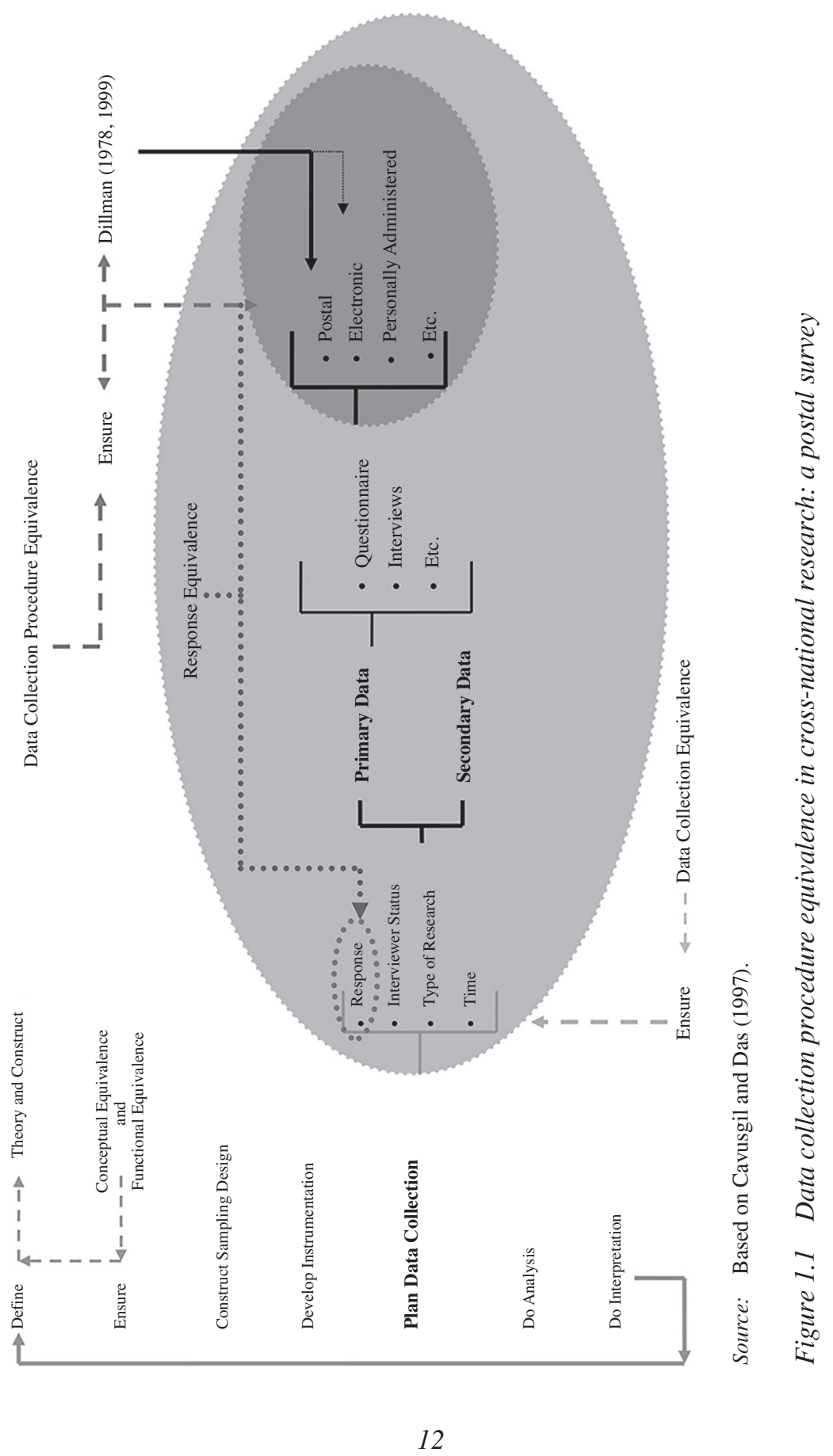

Pervez N. Ghauri and Agnieszka Chidlow - 9781784713171 
(e.g. German as used in Germany or Austria, English in the United Kingdom or the United States). During the data collection phase, timing of data gathering in different countries, interviewer status, type of research and response equivalence are really important (Sekaran, 1983; Nasif et al., 1991; Cavusgil and Das, 1997; Herk et al., 2005). Thus, to provide equivalence within the data collection stage, great effort should be made to ensure that data collection in the different research places are as simultaneous as possible, as this enhances the comparability of the data collected. The researcher should also emphasise the status and authority of the data collection process as different countries have different understandings of power and authority (Hofstede, 1980). Furthermore, researchers are encouraged to use a mixed-method approach for gathering data to give both static and dynamic pictures of research sites. Finally, it is important to state that 'response equivalence can be ensured by adopting uniform data collection procedures in all the cultures in which a problem is being investigated' (Sekaran, 1983, p. 63).

As researchers are open to the use of many techniques in gathering crossnational data to warrant data collection equivalence, it is adequate to say that different methods will require different data collection procedures. Considering Figure 1.1 and focusing on primary data collection methods - mainly those that use a questionnaire as a tool for data gathering - it is critical to say that different administration procedures can be used by researchers depending on the ways in which the questionnaire is sent out to potential respondents (e.g. a postal or a personally administered questionnaire). For example, a researcher chooses to send out a questionnaire by mail, then a comprehensive framework of administration procedures developed by Dillman (1978) could be used to ensure data collection procedure equivalence. As administration procedures are critical to achieving a sufficient response rate, establishing data collection procedure equivalence would enable researchers to establish equivalence in the information so collected. Such an outcome is possible because the issues of equivalence are linked to the stages in the research process; for example, equivalence of administration and equivalence of responses are linked to the phase in the research process where the instrument is developed.

Before discussing the system of administration procedures that could ensure equivalence in administration and responses for a mail survey developed by Dillman (1978), attention needs to be paid to the sources of bias that could be found in survey methodologies in emerging economies.

When undertaking comparative survey research, scholars face at least four potential sources of bias, any of which can make the study results unacceptable. These sources of error include: sampling error, non-coverage error, measurement error and non-response error (Groves, 1989, 2004; Dillman, 1991; Weisberg, 2005). ${ }^{3}$ Challenges to employing quality postal surveys require attempts to eliminate, or at least reduce, all four types of error. 


\section{Research handbook of marketing in emerging economies}

Sampling error occurs when a sample rather than the whole population is surveyed. It is the aspect of survey quality, examined through inferential statistics applied to sample survey results, from which conclusions about significant differences in the population are achieved. It is important to state that in comparative research, sampling error "should be referenced and standardised with regards to the extent of presence of the underlying statistical assumptions in each culture or country' (Cavusgil and Das, 1997, p. 87). Results ought to be presented in terms of comparable statistical terms and estimates (Brock, 2003).

Non-coverage error arises when some members of the population are not covered by the sampling frame and therefore have no possibility of being selected into the sample. Samiee and Jeong (1994), among others, proposed that paying close attention to the sample frame in the countries being studied, and ensuring sample selection in cross-national research, can increase withinsample homogeneity.

Measurement error takes place when the measure obtained fails to reflect the accurate extent to which the subject possesses the attribute being measured. Error may occur due to, for example, flaws in scale design, instrument invalidity and inadequate application of the scale. However, various steps have been proposed in comparative research literature to minimise the measurement error while also ensuring measurement equivalence (Hult et al., 2008).

Non-response error appears when members of the sample population do not respond to the survey questions. A significant amount of research on improving mail survey methods has focused on response rates and a generally accepted proxy for non-response error has been established (Heberlein and Baumgatner, 1978; Eichner and Habermehl, 1981; Cycota and Harris, 2006; Baruch and Holtom, 2008). This almost singular focus on response rates takes place because high non-response bias has long been considered the major drawback of postal surveys. Just as important, however, is the awareness fostered by much of the comparative research literature that such studies could be successful if uniform administration procedures were identified, as equivalence of administration procedures and equivalence of responses are linked during the research process. Maintaining equivalence in data collection procedures might appear straightforward (Hult et al., 2008). However, in spite of all efforts made, the nature of international business research poses a threat and often leads to disparities in data collection procedures (Eichner and Habermehl, 1981). Hence, the establishment of appropriate and comparable survey data collection techniques is a crucial element of rigorous scholarship, as it can minimise threats to the validity and reliability of gathered data. A failure to do so could have significant consequences for knowledge creation in emerging economy contexts, particularly in comparative research (Mullen, 1995; Singh, 1995). 


\section{DILLMAN'S FRAMEWORK FOR MAIL SURVEY DATA COLLECTION}

Guided by social exchange theory, Don A Dillman (1978) proposed in the late 1970s a comprehensive framework for mail survey data collection known in the literature as the Total Design Method (ToDM). According to social exchange theory (Blau, 1964; Homans, 1973), questionnaire recipients are most likely to complete and return a questionnaire if they expect that the perceived benefits of doing so will outweigh the perceived costs (material and psychological) of responding. As a result the researcher, whether in international and/or domestic market settings, needs to minimise the expected costs and maximise the expected benefits of participation. Three elements are crucial for reinforcing this kind of behaviour: rewards, costs and trust. In simple terms rewards are what one anticipates to gain from a particular activity, costs are what one gives up or spends to obtain the rewards, and trust is the expectation that in the long term the rewards of doing something will offset the costs (Dillman, 1978). The most important strength of the ToDM is a set of procedures for increasing response rates and decreasing the non-response errors. ${ }^{4}$

Among the procedures, and of great interest to this chapter, four carefully spaced mailings to potential respondents are proposed. These are, first, a questionnaire mailing. This questionnaire is mailed in an envelope, along with a stamped and addressed return envelope and a detailed covering letter. Second, a postcard is sent to all potential respondents one week after mailing the questionnaire, thanking them for their co-operation and reminding those who have not yet responded that it is important to co-operate. Third, two weeks later a second copy of the questionnaire is sent out to those who have not yet sent in the completed questionnaire, along with a reminder letter that their replies have not yet been received. Finally, four weeks later, ${ }^{5}$ a third copy of the questionnaire is mailed, this time by certified mail, to emphasise the importance of the survey. A note is also added in this procedure to remind potential respondents of the importance of their response for the success of the survey.

Under a social exchange approach, contact methods that are different from ones previously used are generally more powerful than a repetition of a previously used method. Individuals with whom the first contact was successful will not be subject to receiving a replacement questionnaire. As a result, later contacts need to be varied in an effort to increase their effectiveness with non-respondents. Therefore, it is important that each communication method differs from the previous one to convey a sense of appropriate renewal of an effort to communicate. Each of these delivery contacts described above builds upon past research (Dillman et al., 1974; Heberlein and Baumgartner, 1978), showing that a distinctively different final contact improves response to mail surveys. In addition, it has been shown in the literature that multiple contacts 
have a significantly greater collective capability for influencing response rates than any other technique for increasing response to mail surveys (Scott, 1961; Linsky, 1975; Dillman, 1978).

Taking into account the globalisation of markets, the surge of mail survey techniques (Dillman, 1972; Dillman and Sangster, 1990) and the influence of sometimes conflicting pressures from groups with much influence over how surveys get done, Dillman $(1999,2000)$ modified the original ToDM in the late 1990s and called it the Tailored Design Method (TaDM). One of the new features ${ }^{6}$ of the TaDM is the change in the number of contacts. Here the use of five not four contacts are described. The new contact added to the existing contacts in ToDM, as described above, was a brief prenotice letter. This is sent to potential respondents a few days prior to mailing the questionnaire as a special mail. It aims to signal that a questionnaire for an important survey will arrive in a few days and that the person's response would be greatly appreciated.

Dillman's intention in designing each aspect of the implementation system, from pre-notice letter to return envelopes, was to create a positive salience where each element of the process is noticeable, but in a way that creates a positive impression and that increases a sense of reward, diminishes perceived costs and creates trust. The overall impression that is established depends not only on individual contacts, but also on the consistency among those contacts. Therefore, it is important that each contact should not be thought of as standing alone, but as part of an overall implementation system for which a change in one part is likely to have unintended consequences for another. In addition, none of the contacts stated above should be omitted because either the ToDM or the TaDM should be seen as a package of procedures that interact with each other to produce a maximum response rate.

\section{THE EFFICIENCY OF DILLMAN'S FRAMEWORK TO CROSS-NATIONAL RESEARCH}

Since the development of the ToDM technique its adaptation has led to an increase in the number of mail surveys, which have become one of the most common forms for gathering data in business research (Dillman, 1991). Because the ToDM was developed in the United States, Goyder (1982, p. 533), refereeing Ladd's (1980) work, points out that return rates on mail surveys would be lower in cultures different from the United States due to the "higher legitimacy of surveying in America'. However, this claim is no longer applicable, since there have been investigations carried out in Europe, Asia and Australia on whether the ToDM was a nation-bound survey methodology and proved otherwise. Greatz (1985) assessed the feasibility of using the 
implementation procedures proposed by the ToDM in Australia and found that multiple contacts with potential respondents yielded high response rates and good data quality. His results were comparable with those obtained in the United States. De Leeuw and Hox (1988) analysed the efficiency of the personalisation of a covering letter and reminder by certified mail (i.e. response-increasing factors of the ToDM) on a sample of the Dutch population. They found that response-stimulating factors have a statistically significant effect on the number of completed questionnaires and data quality, and that response rates do not differ to a great extent from those obtained in the United States. Another study comparing the appropriateness of the ToDM (i.e. the usefulness of non-monetary incentives) in the Netherlands is that of Nederhof (1983). He showed that the use of an incentive positively influences the speed and quality of survey results. The results he obtained were similar to those in the American literature (see e.g. Brennan, 1958; Watson, 1965) indicating the cross-cultural effectiveness of the ToDM method originally developed in the United States. Rada (2000) examined the usefulness of Dillman's implementation procedures from the TaDM on response rates in Spain and found that multiple contacts do indeed increase the number of returned questionnaires. He also pointed out that his results did not really differ from those obtained by other researchers on efficiency of the ToDM in countries such as the United States, the Netherlands and Australia. In a comparative study of the viability of the ToDM in Japan and the United States, Jussaume and Yamada (1990, p. 226) showed that 'mail surveys are a feasible research tool in Japan and potentially in other cultures where the majority of the intended universe is literate, can be sampled, and can be contacted through a dependable postal system'. Their results have shown that the theoretical foundations of the ToDM are not only bound to certain Western countries and that consideration of the theoretical base is the key to implementing the ToDM in foreign settings.

Based on the above, the fact that methodological data obtained from different countries under similar conditions is comparable to those in the United States suggests that the generalisability of findings may not necessarily be limited to one nation or continent, as claimed by Goyder (1982).

\section{THE ANALYTICAL APPROACH}

To investigate 'if' and 'how' cross-national researchers report on mail survey administration procedures, a comprehensive and systematic content analysis of the Journal of International Business Studies (JIBS), International Business Review (IBR), Journal of World Business (JWB) and Management International Review (MIR) was carried out for publications between 2000 


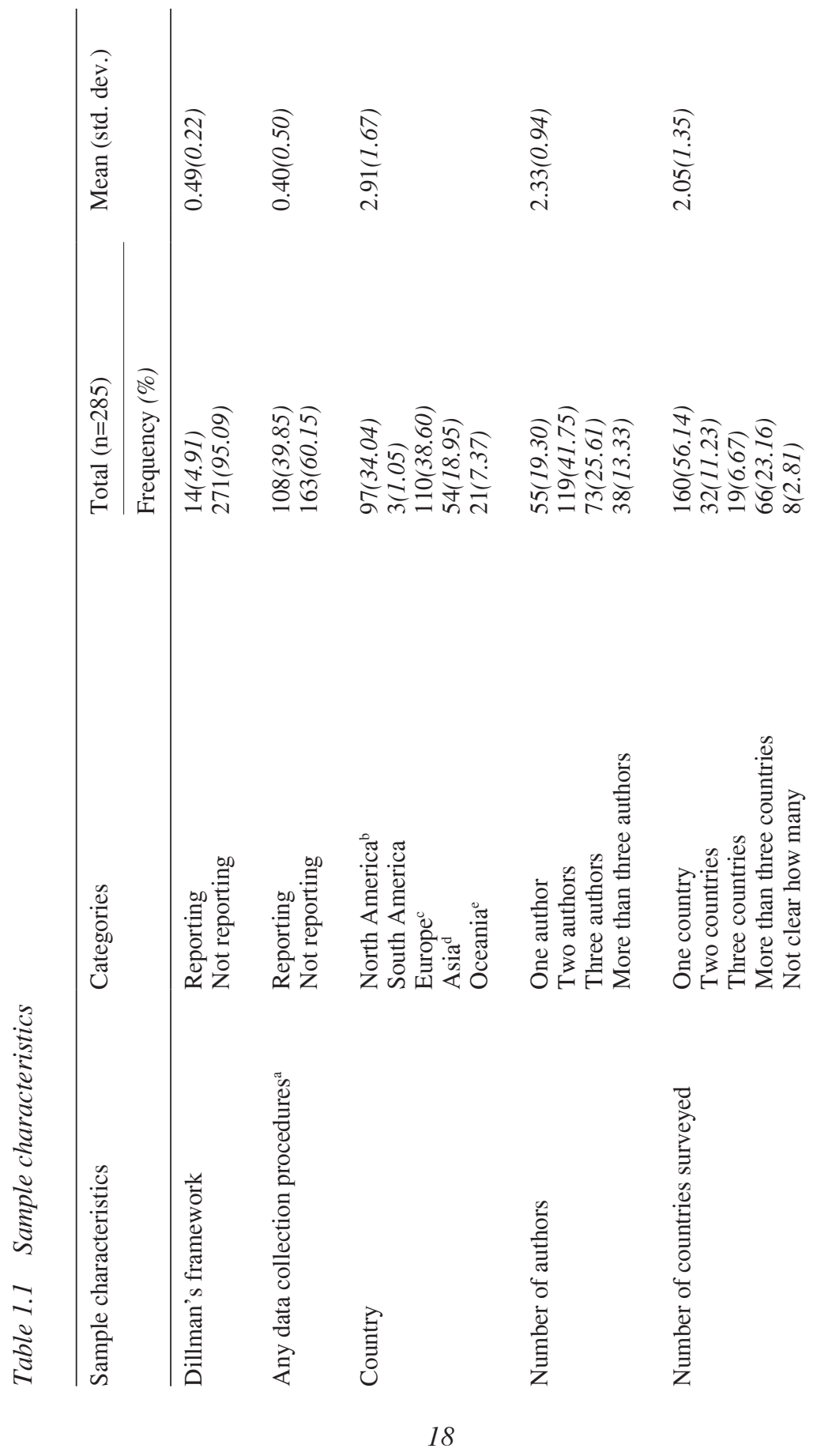




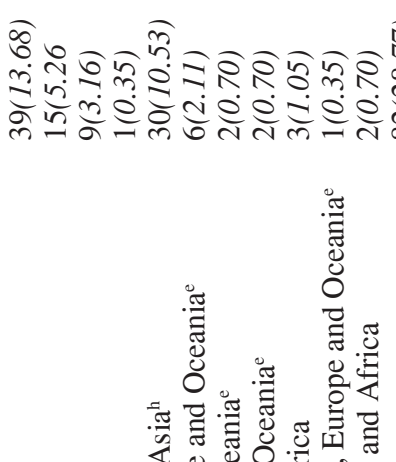

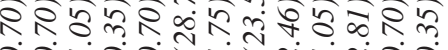

ฟิจิ

गुं

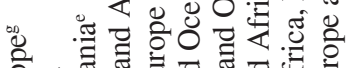

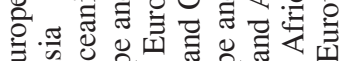

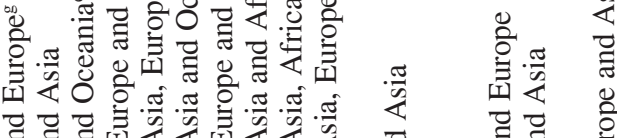

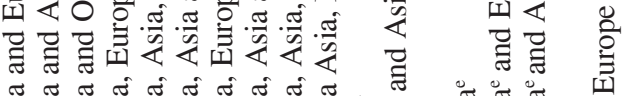

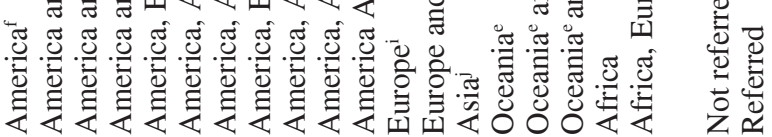

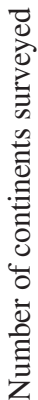

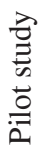



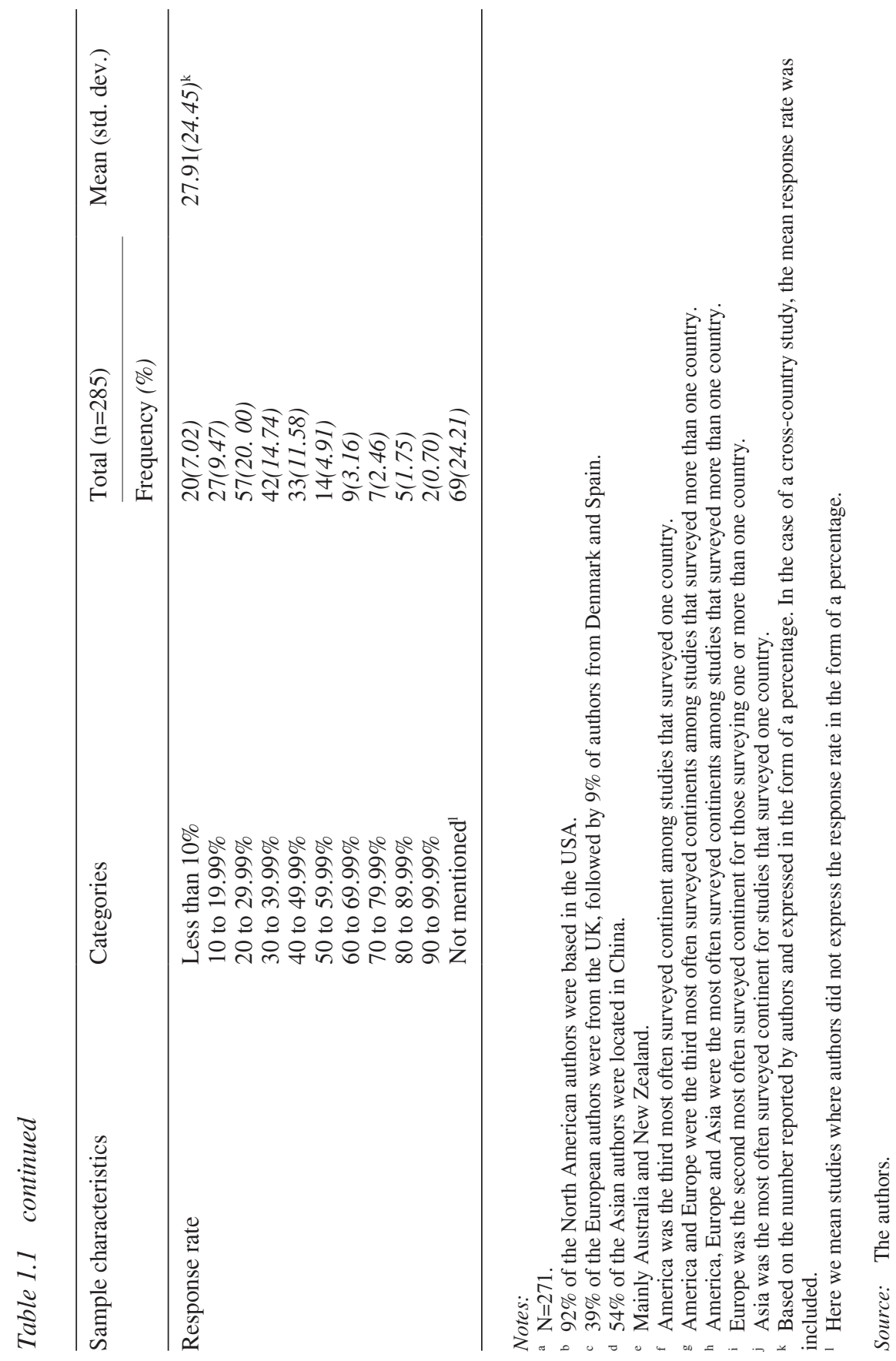
and 2008. These four journals were chosen because they are highly ranked and are 'key' cross-country business-specific journals that contain a solid crosssection of articles (Platt, 1996; DuBois and Reeb, 2000; Piekkari et al., 2009).

Our data collection process consisted of, first, identifying studies one-by-one through individual on-line access to the journal using the library's electronic resources at the authors' institutions. The only exception was MIR, where studies were located using electronic access to the journal plus the examination of hard copies of special and focus issues kindly supplied to authors from the journal's editor-in-chief's office. ${ }^{7}$ Second, every article (omitting editorials, commentaries and award winning) published in the four journals, in the stated period, was categorised based on the type of data collection used by authors (e.g. primary, secondary or both). Within the primary data category, each article was grouped as a questionnaire (i.e. where only a questionnaire was used for data collection) or as a questionnaire plus other primary data techniques (e.g. interviews, focus groups). Further, the questionnaire category was re-grouped into the following sub-categories: surface mail, electronic mail, facsimile message, personally administered, internal mail and mixed method. This was undertaken to examine in more detail the ways through which a questionnaire was delivered to potential respondents.

In situations where a distribution method was not mentioned by authors, a study was placed in the 'not mentioned' category. This identification was based on the method or methods used for data collection by the authors and reported in the methodology section of the particular papers. Finally, the articles were coded in a search for the multi-contact strategies developed by Dillman (1978, 1999, 2000) as discussed above. The coding process was undertaken shortly after a sample of articles was coded to establish an inter-coder agreement (Tinsley and Weiss, 1975; Nederhof, 2002). The inter-rater reliability was achieved at 84 per cent $(\alpha=0.843)$. The result was comparable to other codings of published studies (Boyd et al., 2005; Hult et al., 2008) and allowed us to undertake the data collection process. Any confusions relating to the coding process were resolved by discussions between authors.

In total, 652 out of 1,440 papers published in the four journals under the investigated period used a primary data collection method, accounting for 45 per cent of all articles. Overall, 348 (53 per cent) of the 652 studies were identified as using a questionnaire as the only data collection method.

To examine the pre-set objectives, it was decided to include only studies that utilised a mail survey as a primary data collection method for the following reasons. First, because mail surveys are still popular ways of gathering data by researchers (Yang et al., 2006). Second, the theoretical framework proposed by Dillman in 1978 was developed for postal survey data collection. Finally, the goal was to minimise any research type confounds with regards to data collection equivalence issues. 


\section{Research handbook of marketing in emerging economies}

Based on the above set of criteria, 285 articles were included in our analysis. The characteristics of the samples presented in Table 1.1 point out that only a handful of studies (14 in total or just 5 per cent) reported Dillman's framework for postal data collection techniques. In addition, out of the remaining 271 studies only 108 (40 per cent) reported any of the data collection procedures proposed by Dillman (1978, 1999). Furthermore, for most of the examined papers (110 or 39 per cent of the 285 articles) their authors were located in Europe, followed by North America (97 or 34 per cent) and Asia (54 or 19 per cent). The largest percentage of the European authors (43 or 39 per cent of the 110 articles) was from the United Kingdom, followed by Denmark and Spain (10 or 9 per cent for each of these countries). ${ }^{8}$ In total, 119 articles were written by two authors, 73 by three authors and 55 had single authorship. Most frequently authors researched one country only (in 160 articles), followed by more than three (66 articles) and two in 32 articles. The continent most surveyed by authors was Europe in 82 of the articles, followed by Asia and the Americas. More than half of the investigated studies (183 or 64 per cent) used a pilot study to pre-test the postal questionnaire. The most frequently reported response rates were between 20 and 29.99 per cent (in 57 papers or 20 per cent) with a mean response rate of 28 per cent, a slightly higher percentage than that obtained by Yang et al. (2006) for postal surveys reported in articles in international business journals published between 1992 and 2003.

\section{RESULTS FROM THE NUMBER OF COUNTRIES SURVEYED BY RESEARCHERS}

Table 1.2 displays the results of either reporting or not reporting mail survey data collection procedures by the number of countries surveyed by authors. ${ }^{9}$

Table 1.2 shows that out of 160 studies that surveyed one country, 77 studies (48 per cent) referred to postal survey data collection procedures. Furthermore, it seemed that the most common procedures utilised by authors that surveyed one country were follow-ups (in 41 articles or 26 per cent), and the least common technique was a reminder (in 18 studies or 12 per cent). In addition, the findings indicate that statistically significant results were only found for reporting incentives $\left(\chi^{2}=8.09, \mathrm{p}=0.04\right)$ and reminders $\left(\chi^{2}=7.75, \mathrm{p}=0.05\right)$ among studies that surveyed one country. None of the studies that surveyed one country used a thank you letter as a postal data collection procedure.

Table 1.2 indicates that only 35 ( 30 per cent) out of 117 studies that surveyed more than one country referred to mail survey data techniques. The findings also suggest that the most frequent data collection procedures were incentives and follow-ups (both in 16 studies or 14 per cent), and the least used technique was a pre-notice letter (in seven studies or 6 per cent). In addition, our findings 


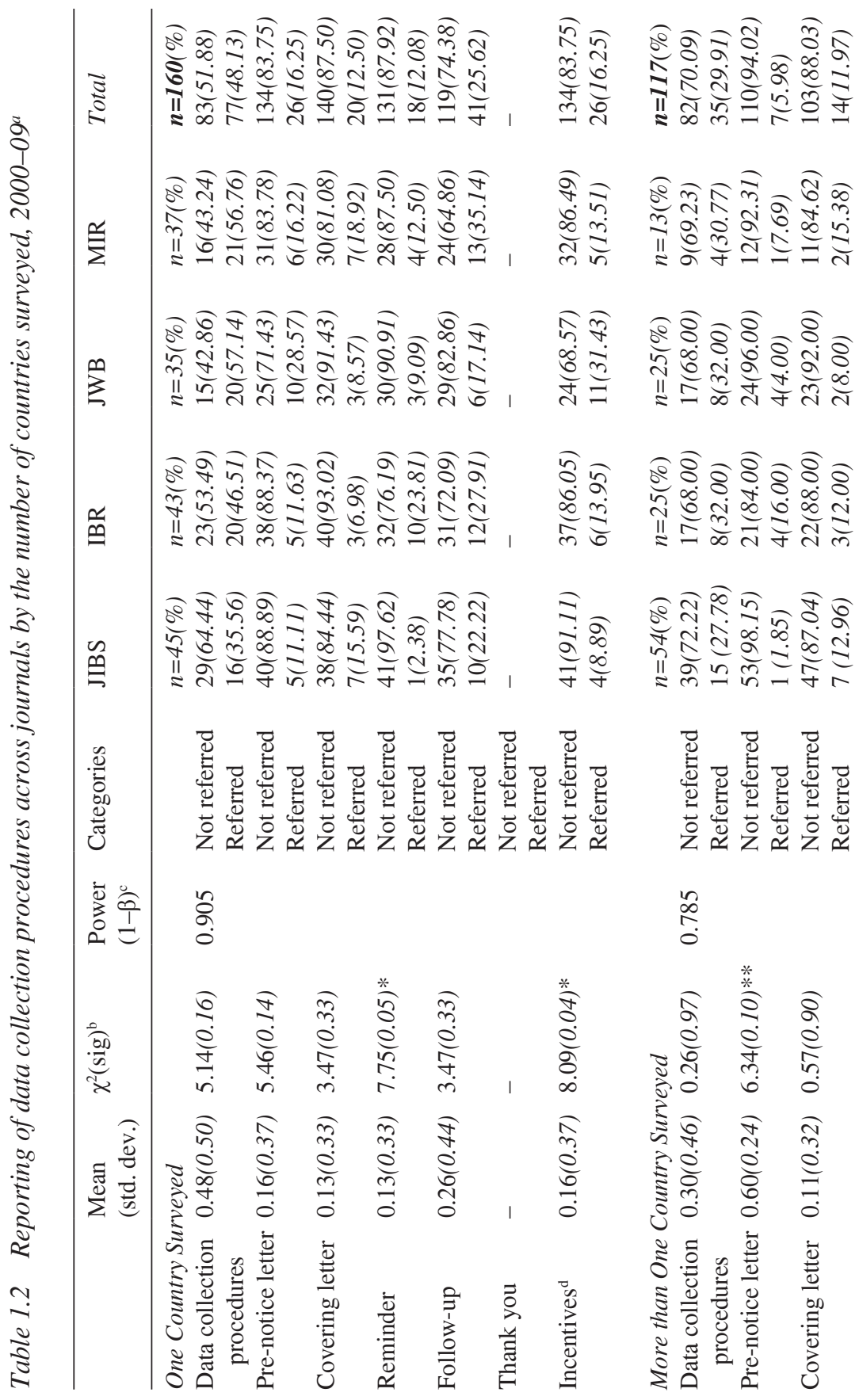




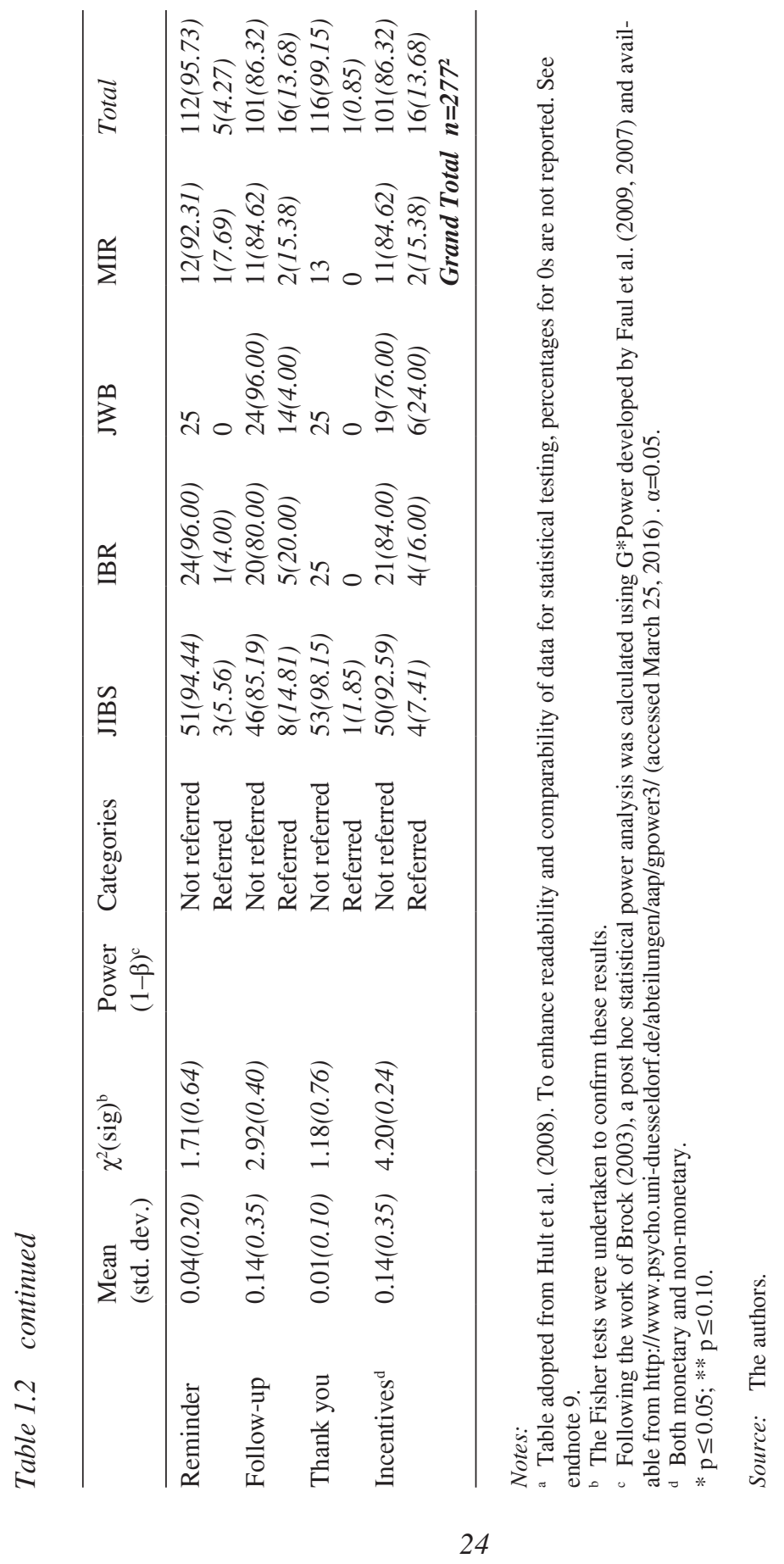


point out that statistically significant results were only found for reporting a pre-notice letter $\left(\chi^{2}=6.34, \mathrm{p}=0.10\right)$ as a data collection strategy amid studies that surveyed more than one country across all journals.

Overall, Table 1.2 shows that so far authors have not been rigorous about reporting data collection procedures used when collecting data via a postal survey. This fact is rather surprising, especially with regard to cross-national studies where such issues should be rigorously considered to ensure data collection equivalence (Chidlow et al., 2015).

\section{CONCLUSIONS}

In a period when cross-country researchers are confronted with a trend of increasing unwillingness by the general public to participate in mail survey research, the success of postal surveys remains conditional upon following proper procedures for data collection and the implementation of proven strategies for stimulating responses (e.g. Eichner and Habermehl, 1981; Cycota and Harris, 2006; Baruch and Holtom, 2008; Chidlow et al., 2015).

This chapter indicates that when undertaking cross-national comparative studies, equivalence in data collection procedures is of utmost importance for achieving comparable and generalisable results (Sekaran, 1983; Singh, 1995; Herk et al., 2005). Although complete equivalence might never be possible (Venuti, 1993; Vermeer, 1998), all necessary attempts have to be made to achieve equivalence. Thus, the objective of this chapter has been to investigate the mail survey administration procedures among international scholars, in order to seek the establishment of data collection procedure equivalence in cross-cultural research for emerging economy research in marketing and international business. Achieving procedure equivalence in emerging economies is a very important issue because it enhances the validity, reliability and comparability of research findings.

Despite the usage of either ToDM or TaDM, we detected inadequate emphases on data collection procedures. The reasons for this are yet to be investigated. It is possible that even if the equivalence of data collection procedures has not been stressed or pointed out in the investigated papers, it has been faithfully followed. It is our belief that considering the significance of data collection across countries, a greater attention needs to be focused on reporting such procedures to be able to establish the equivalence of data collection procedures and ensure the validity of our research.

It has to be pointed out that the purpose of this chapter is not to criticise previous research; rather, it is to recognise and bring attention to the importance of an ongoing methodological debate within the conduct of comparative research. Our hope is that this chapter will form a useful basis for those researchers 


\section{Research handbook of marketing in emerging economies}

embarking upon a journey of enhancing the importance of adequate reporting of survey administration procedures, and of ensuring data collection procedure equivalence during the collection process of their cross-national data in emerging economies. Such an undertaking is important because without the establishment of data collection procedure equivalence in cross-country research in emerging market contexts, the issue pointed out by Hult et al. (2008) translates into questioning the reliability and validity of findings. To minimise that threat it is therefore essential to ensure comparable mail survey data collection procedures to allow researchers to gather reliable data across dissimilar markets. While ensuring consistency in data collection methods may seem straightforward, cross-national differences might explain the variations (Craig and Douglas, 2000; Hult et al., 2008). Such disparities could be overcome if researchers become more thorough in reporting, and explaining how and why particular strategies were used for data gathering (Chidlow et al., 2015).

\section{NOTES}

1. According to Pike (1966) the terms 'emic' and 'etic' stem from a linguistic distinction between phonemics and phonetics.

2. Please refer to Cavusgil and Das (1997) for a more detailed explanation of the model.

3. For other potential sources of bias in research projects refer, for example, to Cox (1974) or Cavusgil and Das (1997).

4. For other details of the ToDM and how they are integrated to make a holistic effect please see Dillman (1978).

5. Or seven weeks after the first questionnaire was sent out.

6. For more details please see Dillman (2000).

7. At the time of data collection, none of the special and focus issues were available electronically.

8. This data is not present in Table 1.2.

9. Excluding eight studies for which it was not clear how many countries were surveyed. See Table 1.1 for sample characteristics.

\section{REFERENCES}

Adler, N.J. (1983). 'Cross-cultural management research: The ostrich and the trend'. Academy of Management Review, 8(2), 226-32.

Baruch, Y. and B.C. Holtom (2008). 'Survey response rate levels and trends in organizational research'. Human Relation, 61(8), 1139-60.

Berry, J.M., and P. Dasen (1974). Introduction to Culture and Cognition. London: Methuen.

Berry, J.M. (1999). 'On cross-cultural comparability'. International Journal of Psychology, 4(2), 119-28.

Blau, P.M. (1964). Exchange and Power in Social Life. New York, NY: John Wiley \& Sons.

Brennan, R.D. (1958). 'Trading stamps as an incentive in mail surveys'. Journal of Marketing, 22, 306-17.

Brock, J.K.-W. (2003). 'The "power" of international business research'. Journal of International Business Studies, 34(1), 90-9.

Boyd, B.K., S. Gove, and M. Hitt (2005). 'Construct measurement in strategic management research: Illusion or reality?' Strategic Management Journal, 26(3), 239-57. 
Cavusgil, S.T. and A. Das (1997). 'Methodological issues in empirical cross-cultural research: A survey of the management literature and a framework'. Management International Review, 37(1), 71-96.

Chidlow, A., E. Plakoyiannaki, and C. Welsh (2014). 'Translation in cross-language international business research: Beyond equivalence'. Journal of International Business Studies, 45(5), $562-82$.

Chidlow, A., P. Ghauri, S. Yeniyurt, and S.T. Cavusgil (2015). 'Establishing rigor in mail survey procedures in international business research'. Journal of World Business, 50(1), 26-36.

Coviello, N.E., and M.V. Jones (2004). 'Methodological issues in international entrepreneurship research'. Journal of Business Venturing, 19(4), 485-508.

Cox, E.P. (1974). 'Research for Business Decisions: An Interdisciplinary Approach'. Bureau of Business Research, Austin, TX: The University of Texas.

Craig, C.S., and S.P. Douglas (2000). International Marketing Research. Second edition. New York, NY: John Wiley \& Sons.

Cycota, C.S., and D.A. Harris (2006). 'What (not) to expect when surveying executives: A metaanalysis of top managers response rates and techniques over time'. Organizational Research Methods, 9(2), 133-60.

De Leeuw, E.D., and J.J. Hox (1988). 'The effects of response-stimulating factors on response rates and data quality in mail surveys: A test of Dillman's total design method'. Journal of Official Statistics, 4(3), 241-9.

Dillman, D.A. (1972). 'Increasing mail questionnaire response for larger samples of general public'. Public Opinion Quarterly, 35(3), 254-7.

Dillman, D.A. (1978). Mail and Telephone Surveys: The Total Design Method. New York, NY: John Wiley \& Sons.

Dillman, D.A. (1991). 'The design and administration of mail surveys'. Annual Review of Sociology, 17, 225-49.

Dillman, D.A. (1999). 'Mail and other self-administered surveys in the 21st century: The beginning of a new era'. The Gallup Research Journal, Winter/Spring, 121-40.

Dillman, D.A. (2000). Mail and Internet Surveys. The Tailored Design Method. Second edition. New York, NY: John Wiley \& Sons.

Dillman, D.A., and R.L. Sangster (1990). Mail Surveys: A Comprehensive Bibliography 19741989, Technical Report. Pullman: Washington State University.

Dillman, D.A., J.A. Christenson, E.H. Carpenter, and R. Brooks (1974). 'Increasing mail questionnaire response: A four-state comparison'. American Sociological Review, 39, 744-56.

DuBois, F.L., and D.M. Reeb (2000). 'Ranking the international business journals'. Journal of International Business Studies, 31(4), 689-704.

Eichner., K., and W. Habermehl (1981). 'Predicting response rates in mail questionnaires'. American Sociological Review, 46(3), 361-3.

Faul, F., E. Erdfelder, A.-G. Lang, and A. Buchner (2007). 'G*Power 3: A flexible statistical power analysis program for the social, behavioural, and biomedical sciences'. Behavior Research Methods, 39(1), 175-91.

Faul, F., E. Erdfelder, A. Buchner, and A.-G. Lang (2009). 'Statistical power analyses using G*Power 3.1: Tests for correlation and regression analyses'. Behavior Research Methods, 41(4), 1149-60.

Ghauri, P.N., and K. Gronhaug (2010). Research Methods in Business Studies. A Practical Guide. Third edition. Harlow: Pearson Education Ltd.

Goyder, J.C. (1982). 'Further evidence on factors affecting response rates to mailed questionnaires'. American Sociological Review, 47(4), 550-53.

Greatz, B. (1985). 'The potential of mail surveys'. Australian and New Zealand Journal of Sociology, 21(3), 445-55.

Green, R.T., and P.D. White (1976). 'Methodological considerations in cross-national consumer research'. Journal of International Business Studies, 14(1), 81-7.

Groves, R.M. (1989). 'Research on survey data quality'. Public Opinion Quarterly, 51, 156-72.

Groves, R.M. (2004). Survey Errors and Survey Costs. New York, NY: John Wiley \& Sons.

Harzing, A.-W. (1997). 'Response rates in international mail surveys: Results of a 22-country study'. International Business Review, 6(6), 641-65. 


\section{Research handbook of marketing in emerging economies}

Herberlein, T.A., and R. Baumgartner (1978). 'Factors affecting response rates to mailed questionnaires: A quantitative analysis of the published literature'. American Sociological Review, 43, 447-62.

Herk, H., Y.H. Poortinga, and T.M.M. Verhallen (2005). 'Equivalence of survey data: relevance for international marketing'. European Journal of Marketing, 39(3/4), 351-64.

Hofstede, G. (1980). Culture's Consequences: International Differences in Work-Related Values. Beverly Hills, CA: Sage.

Homans, C.G. (1973). Social Behaviour. London: Routledge and Kegan.

Hult, G.T.M., D.J. Ketchen, D.A. Griffith, C.A. Finnegen, T. Gonzales-Padron, N. Harmancioglu, Y. Huang, M.B. Talay, and S.T. Cavusgil (2008). 'Data equivalence in cross-cultural international business research: Assessment and guidelines'. Journal of International Business Studies, 39(6), 1027-44.

Jobber, D., and J. Saunders (1988). 'An experimental investigation into cross-national business survey response rate'. Journal of International Business Studies, 19(3), 483-9.

Jobber, D., H. Mirza, and K.H. Wee (1991). 'Incentives and response rates to cross-national business surveys: A logit model analysis'. Journal of International Business Studies, 22(4), 711-21.

Jussaume, R.A., and Y. Yamada (1990). ‘A comparison of the variability of mail surveys in Japan and the United States'. Public Opinion Quarterly, 54(2), 219-28.

Kjeldgaard, D., F. Csaba and G. Ger (2006). 'Grasping the global: Multi-sited ethnographic market studies'. In R.W. Belk (Ed.), Handbook of Qualitative Research Methods in Marketing, Cheltenham, UK and Northampton, MA, USA: Edward Elgar Publishing, 521-34.

Ladd, E.C. (1980). 'Polling and the press: the clash of institutional imperatives'. Public Opinion Quarterly, 44, 574-84.

Linsky, A.S. (1975). 'Stimulating responses to mailed questionnaire: A review'. Public Opinion Quarterly, 39, 82-101.

Mullen, M.R. (1995). 'Diagnosing measurement equivalence in cross-national research'. Journal of International Business Studies, 26(3), 573-96.

Nasif, E.G., H. Al-Daeaj, B. Ebrahim, and M.S. Thibodeaux (1991). 'Methodology problems in cross-cultural research: An updated review'. Management International Review, 31(1), 79-91.

Nederhof, A.J. (1983). 'The effects of material incentives in mail surveys: Two studies', Public Opinion Quarterly, 47(1), 102-11.

Nederhof, K.A. (2002). The Content Analysis Guidebook. Thousand Oaks, CA: Sage.

Peng, T.K., M.F. Peterson, and Y.-P. Shyi (1991). 'Quantitative methods in cross-national management research: Trends and equivalence issues'. Journal of Organizational Behaviour, 12(2), 87-107.

Piekkari, R., C. Welch, and E. Paavilainen (2009). 'The case study as disciplinary convention: Evidence from international business journals'. Organisational Research Methods, 12(3), 567-89.

Pike, K. (1966). Language in Relation to a United Theory of the Structure of Human Behaviour. The Hague, the Netherlands: Mouton.

Platt, J. (1996). A History of Sociological Research Methods 1920-1960. Cambridge: Cambridge University Press.

Przeworski, A. and H. Teune (1966). 'Equivalence in cross-national research'. Public Opinion Quarterly, 30(4), 551-68.

Rada, V.D. (2000). 'Mail surveys using Dillman's TDM in a southern European country: Spain'. International Journal of Public Opinion Research, 13(2), 159-72.

Reynolds, N.L., A.C. Simintiras, and A. Diamantopoulos (2003). 'Theoretical justifications of sampling choices in international marketing research: Key issues and guidelines for research'. Journal of International Business Studies, 34(1), 80-89.

Samiee, S., and I. Jeong (1994). 'Cross-cultural research in advertising: An assessment of methodologies'. Journal of the Academy of Marketing Science, 22(2), 205-17.

Schaffer, B.S., and C.M. Riordan (2003). 'A review of cross-cultural methodologies for organizational research: A best-practices approach'. Organizational Research Methods, 6(2), 169-215.

Sekaran, U. (1981). 'A cross-cultural analysis of the influence of individual and job characteristics on job involvement'. Applied Psychology, 30, 51-64. 
Sekaran, U. (1983). 'Methodological and theoretical issues and advancements in cross-national research'. Journal of International Business Studies, 2, 61-74.

Scott, C. (1961). 'Research on mail surveys'. Journal of the Royal Statistical Society, 124, 143-205.

Singh, J. (1995). 'Measurement issues in cross-national research'. Journal of International Business Studies, 14(2), 61-73.

Tinsley, H.E.A., and D.J. Weiss (1975). 'Interrater reliability and agreement of subject judgements'. Journal of Counselling Psychology, 22, 358-76.

Venuti, L. (1993). 'Translation as cultural politics: Regimes of domestication in English'. Textual Practice, 7(2), 208-23.

Vermeer, H.J. (1998). 'Starting to unmask what translatology is about'. Target, 10(1), 41-68.

Watson, J.J. (1965). 'Improving the response rate in mail research'. Journal of Advertising Research, 5, 48-50.

Weisberg, H.F. (2005). The Total Survey Error Approach: A Guide to the New Science of Survey Research. Chicago, IL: The University of Chicago Press.

Yang, Z., X. Wang, and C. Su (2006). 'A review of research methodologies in international business'. International Business Review, 15(6), 601-17.

Yaprak, A. (2006). 'Measurement problems in cross-national consumer research: The state-of-theart and future research directions'. In S.C. Jain (Ed.), Handbook of Research in International Marketing, Cheltenham, UK and Northampton, MA, USA: Edward Elgar Publishing, 174-90. 